\title{
Multidetector CT in children: current concepts and dose reduction strategies
}

\author{
Rutger A. J. Nievelstein • Ingrid M. van Dam • \\ Aart J. van der Molen
}

Received: 27 October 2009/Revised: 30 March 2010 /Accepted: 6 April 2010 /Published online: 10 June 2010

(C) The Author(s) 2010. This article is published with open access at Springerlink.com

\begin{abstract}
The recent technical development of multidetector CT (MDCT) has contributed to a substantial increase in its diagnostic applications and accuracy in children. A major drawback of MDCT is the use of ionising radiation with the risk of inducing secondary cancer. Therefore, justification and optimisation of paediatric MDCT is of great importance in order to minimise these risks ("as low as reasonably achievable" principle). This review will focus on all technical and non-technical aspects relevant for paediatric MDCT optimisation and includes guidelines for radiation dose levelbased $\mathrm{CT}$ protocols.
\end{abstract}

Keywords Multidetector CT · Technique - Justification . Optimisation · Child

\section{Introduction}

In the last decade, there has been revolutionary development in multidetector CT (MDCT) technology that has contributed to a substantial increase in its diagnostic applications and accuracy, even in children. However, a major drawback of MDCT is the use of ionising radiation and, consequently, the risks of radiation-induced side effects [1-5]. Of these side effects, the induction of cancer is the most important. This is especially true in children, because rapidly dividing cells are

R. A. J. Nievelstein $(\bowtie) \cdot$ I. M. van Dam

Department of Pediatric Radiology, Wilhelmina Children's

Hospital, University Medical Centre Utrecht,

E01.132, P.O. Box 85500, 3508 GA Utrecht, The Netherlands

e-mail: R.A.J.Nievelstein@umcutrecht.nl

A. J. van der Molen

Department of Radiology, C-2S, Leiden University Medical Centre, Leiden, The Netherlands more sensitive to radiation, and children will have more years ahead in which cancerous changes might occur. Although the available evidence on the side effects of lowdose radiation still remains a matter of discussion, it is generally believed that there is a linear-no threshold risk relationship [6-11]. Therefore, we should act as if low-dose radiation may well cause secondary cancer and reduce the medical radiation exposure to children as much as possible, the "as low as reasonably achievable" (ALARA) concept. This explains the current interest of several international scientific organisations and the literature in MDCT dose reduction and optimisation strategies [2, 12-17].

Optimisation of MDCT in children requires first of all a solid understanding of all technical aspects of CT, including the most relevant scan parameters, new dose reduction techniques and the technique of intravenous (IV) contrast material administration. In addition, the smaller size and lack of visceral fat in young children changes the interaction and absorption of radiation and likewise the choice of technique and scan parameters. Although all these issues are pivotal for a successful CT examination, they may become worthless if issues such as justification for scan and patient preparation are ignored. In this review we will discuss the current knowledge on all aspects relevant for MDCT optimisation in children, including justification for scan, patient preparation, technical and scan parameters and contrast administration. Furthermore, we will provide some guidance for several low-dose CT protocols, based on volume CT dose index (CTDIvol) levels.

\section{Justification for scan}

Reducing the radiation dose and its associated risks in children starts with performing $\mathrm{CT}$ in children only when properly 
indicated (justification for scan). To achieve this goal, adequate communication between the referring physician and radiologist is essential. Only with a complete clinical picture will the radiologist be able to make a well-considered decision which imaging modality will be the best choice to answer the clinical question [18]. Moreover this information will help the radiologist optimise the CT technique, reducing the risk of failed and repeated examinations.

In several recent publications it has been suggested that $>30 \%$ of paediatric CT examinations were unnecessary or replaceable by other imaging modalities not using ionising radiation $[1,2,19-21]$. The reasons given for the performance of these unnecessary CT examinations include wrong or debatable indications (e.g., epilepsy, headaches, appendicitis, urolithiasis), medico legal reasons and repeated examinations due to lack of communication between or uncertainty of the referring physicians. Furthermore, some studies have shown that up to $75 \%$ of referring physicians underestimated the radiation dose of CT, while up to $90 \%$ underestimated the potential risks associated with ionising radiation [22-24].

Most of the former data are based on studies from the USA and are not directly comparable to the European situation. For instance, in most European countries US is performed by radiologists and is a widely accepted and more frequently used imaging modality in children, especially for abdominal indications. At our hospital, in 2008 the percentage of pediatric CT examinations was only $4.5 \%$ of the total number of paediatric radiological examinations (approximately 1,400 CT scans out of a total of 31,000 examinations) and this number is still declining. Most paediatric CT examinations were focused on the head (62\%), followed by the thorax (17\%). CT was performed for abdominal indications in only $7 \%$. On the contrary, the percentage of US exams performed in children was approximately $13 \%$ of 31,000 examinations, of which almost $60 \%$ had been performed for abdominal indications. A recent German survey by Galanski et al. [25] showed similar figures for paediatric $\mathrm{CT}$ with most of the examinations being performed in university medical centres with dedicated multidetector CT scanners.

In our opinion, US should be the first-line imaging modality in children for most abdominal, neck and musculoskeletal indications, as children usually lack large amounts of (intra-abdominal) fatty tissue. Even in the thorax, US can be the first-line imaging modality $[26,27]$. Furthermore, the applicability of MRI outside the central nervous system is increasing, making MRI by now the imaging modality of choice for characterisation of liver lesions, in (suspected) inflammatory bowel disease and for most musculoskeletal entities. In onco- logical imaging MRI is also increasingly used, including new functional imaging techniques such as diffusionweighted imaging $[7,28]$. This is of special interest as in oncology, imaging will be repeated several times during follow-up. There are several international guidelines available to help the clinician (and radiologist) in deciding which imaging modality is the best for specific indications. Examples of these are the "ACR Appropriateness Criteria", and the referral guidelines of The Royal College of Radiologists [29, 30].

\section{Optimisation of paediatric CT}

\section{Patient preparation}

To acquire an optimal CT examination adequate prescan patient preparation is as important as the optimisation of the CT technique. Issues that should be addressed are (1) psychological preparation of children and parents (including the scanner environment), (2) the need for sedation or general anaesthesia, (3) oral contrast material preparation, and (4) IV contrast material preparation.

\section{Psychological preparation and need for sedation}

Adequate prescan patient preparation should include:

- Age- and intellect-adapted information to the child and information for the parents about the CT examination (including written information, simulation, coaching or other forms of playing therapy).

- Inviting one or both parents to stay with the child before, during and after the investigation.

- Adaptation of the scanner environment to children (for instance by using a painted curtain covering the CT gantry, and (projection of) paintings on the wall or ceiling).

This will help to reduce the anxiety of the child and positively influence their mood, increasing the success rate of the CT examination without the need for sedation or general anaesthesia. In general, children 5 years of age and older will be able to undergo a CT examination without sedation after thorough patient instruction. However, there are still situations in which sedation or general anaesthesia will be required depending on the type of investigation, age and mental ability of the child and the clinical situation and question. The way sedation and general anaesthesia is organised depends largely on local agreements and legislations, and falls beyond the scope of this article. The interested reader is referred to recent literature on this topic $[31,32]$. 
It is worth mentioning the possibility of fixation by use of a vacuum pillow. Vacuum pillows are composed of an airtight flexible cover filled with small solid polystyrene balls. This pillow can easily be wrapped around the baby or the part of the body to be investigated. By sucking it, the vacuum one creates provides firm but soft fixation, ideal for the fixation of babies or certain parts of the body (e.g., head, shoulder, extremity) in infants and preventing the need for sedation or anaesthesia (Fig. 1).

\section{Oral contrast material}

As small children lack large amounts of intraabdominal fatty tissue, interpretation of a CT of the abdomen will be more difficult than in adults. That is why we prefer US as the imaging modality of first choice for abdominal clinical problems in childhood. If $\mathrm{CT}$ of the abdomen is indicated, adequate oral contrast intake is often essential for the evaluation. Depending on the age of the child, a diluted iodinated or bariumbased oral contrast agent is given by mouth or through a nasogastric tube during $24 \mathrm{~h}$ prior to or $1 \mathrm{~h}$ and $15 \mathrm{~min}$ before the examination (Tables 1 and 2) [33, 34]. In general, adequate opacification of the small intestine and proximal part of the colon is achieved with the latter (biphasic) approach, making it the preferred method in children. The dilution factor of these oral contrast agents $(\mathrm{CM})$ is usually higher than in adults [1$2 \%$ instead of $3 \%$ of iodinated CM (300-350 $\mathrm{mg} \mathrm{I} / \mathrm{ml})]$, which provides better contrast with low tube voltage techniques. In infants and young children a non-ionic iodinated oral contrast agent is often preferred because of the risk of aspiration. These high-density oral contrast

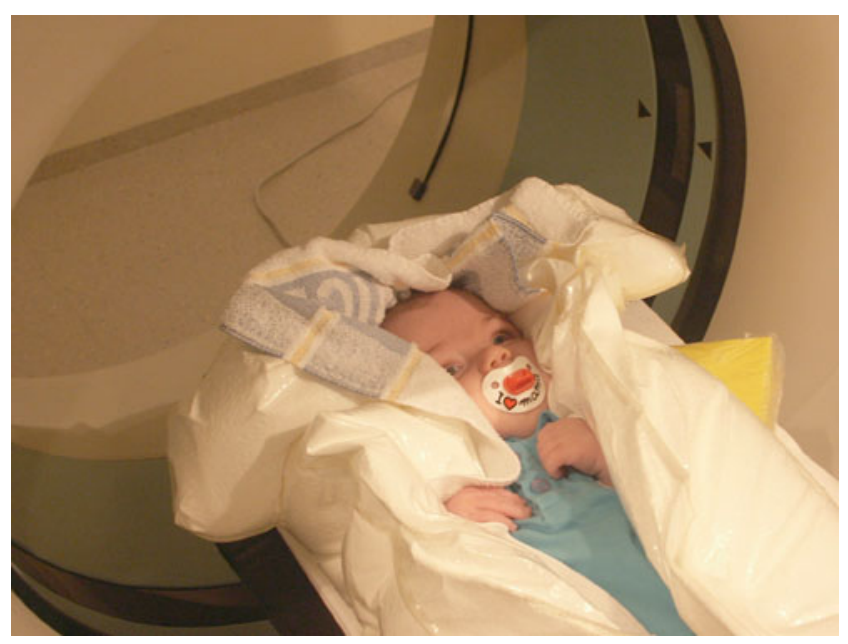

Fig. 1 Illustration of the fixation of a baby using a vacuum pillow (reproduced with permission from the parents)
Table 1 Age-based amounts of oral $\mathrm{CM}$ for a $24 \mathrm{~h}$ preparation protocol

\begin{tabular}{lll}
\hline Age & $\begin{array}{l}\text { 1st dose }(\mathrm{ml}) \text { (total amount } \\
\text { to be divided in 4 portions } \\
\text { over 24h) }\end{array}$ & $\begin{array}{l}\text { 2nd dose }(\mathrm{ml} / \mathrm{kg}) \\
\text { (30min prior to CT) }\end{array}$ \\
\hline$<1$ year & 100 & 15 \\
$1-5$ years & 400 & 15 \\
$5-12$ years & 800 & 15 \\
$>12$ years & $1,000-1,200$ & 15 \\
\hline
\end{tabular}

agents are especially well suited for the differentiation of hypodense or cystic lesions from intestinal loops. However, there is increasing evidence that the use of lowdensity oral contrast agents may be the preferred method for opacification of intestinal loops [35, 36]. Examples of these agents are water, full-fat milk or a polyethylene glycol or mannitol $(1.5 \%)$ suspension. These low-density contrast agents are especially well suited for the evaluation of mucosal lesions of intestinal loops and intraluminal or submucosal bleeding.

\section{Intravenous contrast material}

For the administration of IV contrast material, the use of a power injector instead of hand injection is preferred. Therefore, the largest possible IV cannula should be placed, preferably in the antecubital vein $[33$, $34,37]$. It is advocated to place this cannula in a comfortable environment at the in-patient or out-patient ward and after application of a local anaesthetic gel or ointment (e.g., lidocaine hydrochloride gel, Astra-Zeneca, London, UK). Central venous lines (CVL) or portacath systems can be used but are often restricted by their maximum pressure range of $30-40$ pounds per square inch (psi), whereas the minimum adjustable pressure of the power injector is usually 50 psi. This means that, when using a CVL, one should inject the contrast agent

Table 2 Age-based amounts of oral CM for a biphasic preparation protocol, $1 \mathrm{~h}$ and $15 \mathrm{~min}$ prior to CT examination $[33,34]$

\begin{tabular}{lll}
\hline Age & $\begin{array}{l}\text { 1st dose }(\mathrm{ml}) \\
( \pm 1 \mathrm{~h} \text { prior to CT })\end{array}$ & $\begin{array}{l}\text { 2nd dose }(\mathrm{ml}) \\
(15 \mathrm{~min} \text { prior to CT })\end{array}$ \\
\hline $1-6$ months & $90-120$ & $45-60$ \\
6 months-1 year & $120-180$ & $60-90$ \\
$1-4$ years & $180-270$ & $90-135$ \\
$4-8$ years & $270-360$ & $135-180$ \\
$8-12$ years & $360-480$ & $180-240$ \\
$12-16$ years & $480-600$ & $240-300$ \\
\hline
\end{tabular}


manually for medico legal reasons. However, based on several recent publications and our own experience power injection of IV contrast material through a CVL is possible with a low complication rate [38-41]. Recently, so-called PowerPort (Bard Access Systems Inc, Salt Lake City, UT, USA) implantable portacath systems have become available, combining reliable venous access with the ability for power-injected CM administration. In case of a peripherally inserted central catheter (PICC) or cannula sited on the hand, foot or skull, the contrast material can only be administered safely by manual injection.

The standard contrast material used for IV administration is a non-ionic, low-osmolar contrast agent with a concentration between 240 and $400 \mathrm{mg} \mathrm{I} / \mathrm{ml}$ (most frequently $300 \mathrm{mg} \mathrm{I} / \mathrm{ml}$ ). As yet we are not aware of any indication for the use of high-concentration $\mathrm{CM}$ (370-400 $\mathrm{mg} \mathrm{I} / \mathrm{ml})$ in children, except perhaps in cases of extreme obesity or the need for very low injection rates (e.g., in cases of fine-needle calibres). The standard $\mathrm{CM}$ dose is $2.0 \mathrm{ml} / \mathrm{kg}$ (concentration $300 \mathrm{mg}$ $\mathrm{I} / \mathrm{ml}$ ), which is comparable to $600 \mathrm{mg} \mathrm{I} / \mathrm{kg}$. However, in case of a CT of the brain, neck or thorax usually a dose of $1.5 \mathrm{ml} / \mathrm{kg}(450 \mathrm{mg} \mathrm{I} / \mathrm{kg})$ will suffice. It is safe to increase the dose to $3.0-4.0 \mathrm{ml} / \mathrm{kg}$ (or a maximum of $150 \mathrm{ml}$ ) even in children, assuming that the renal function is normal. This can be of value if simultaneous opacification of the arteries and veins is needed.

In children the circulation time varies widely which makes adequate scan timing more difficult. Furthermore, the size, position and type of cannula will differ among different age groups, with as a consequence varying injection rates (Table 3 ). In general, an injection rate of $2.0 \mathrm{ml} / \mathrm{s}$ suffices for most paediatric indications, especially when younger than 12 years of age. When using a CVL, the injection rate should be maximized to $2.0 \mathrm{ml} / \mathrm{s}$ for safety reasons. An empirically determined fixed delay time usually suffices for most routine indications, especially in the younger age group. However, the routine use of bolus tracking techniques is strongly recommended for most body indications, especially in case of a CT angiography (CTA) or arterial-phase CT [42]. An alternative for scan timing is the test bolus

Table 3 Maximum flow rate adjusted to the size of the IV cannula $[33,34,37]$

\begin{tabular}{ll}
\hline Cannula size (gauge) & Maximum flow rate $(\mathrm{ml} / \mathrm{s})$ \\
\hline 24 & 1.5 \\
22 & 2.5 \\
20 & 4.0 \\
18 & 5.0 \\
\hline
\end{tabular}

technique, although this technique is not suitable in very small children as the total volume of contrast material available is often too small. Both techniques share the disadvantage of additional (monitoring) scans, increasing the radiation dose for the child. This additional dose should be weighed against the benefit of improved and individualized scan timing, and when applied the monitor scans should be obtained with a low-dose technique to limit this additional radiation dose. Table 4 summarises some guidelines for delay timing based on the indication for the MDCT scan. More details on IV CM injection issues in MDCT are given in three recent comprehensive overviews [42-44].

\section{Selective organ shielding}

The use of bismuth shielding of radiosensitive organs (e.g., breast, thyroid gland and eye lens) to reduce organ doses has been suggested [45, 46]. However, these shields may also reduce the amount of radiation reaching the detector ring in some projections and may add noise or artifacts to the images, especially if no standoff pads are used [47]. A fundamental study by Geleijns et al. [48] showed that the reduction in organ dose can also be achieved more efficiently by lowering the tube current. In addition, these shields may complicate the use of dose modulation techniques with the risk of increasing radiation dose to the child. Therefore, it remains to be seen if selective organ shielding will be of any additional benefit if the CT protocols are already maximally optimised for children [47-49]. We will therefore not advocate this method.

\section{Scan and technical parameters}

The scan and technical parameters should be tailored to the size of the child, the body region of interest and the clinical question [33, 34, 50-52]. The primary goal should be to achieve diagnostic image quality instead of optimal image quality in order to minimise the radiation dose to the child. In other words, a certain amount of image noise is acceptable as long as the clinical question can be answered. This is one of the major points of the ALARA principle in paediatric radiology. Unfortunately, established levels of noise on CT images that have been deemed acceptable for diagnostic purposes are still lacking, especially in children.

\section{Number of phases}

Multiphase CT examinations in children should be avoided. The use of precontrast CT scans hardly ever results in clinically relevant extra information and 
Table 4 Guidelines for the selection of the scan delay in CT with IV CM. max maximum; * $\mathrm{BT}_{100}$ or $\mathrm{BT}_{150}$ is the time required to reach a threshold of + $100 \mathrm{HU}$ and $+150 \mathrm{HU}$, respectively, with bolus tracking; ** adaptation of injection time necessary to make sure that scan starts before end CM injection!

\begin{tabular}{|c|c|}
\hline Indication & Scan delay \\
\hline $\begin{array}{l}\text { Routine CT neck } \\
\text { (e.g., lymphoma, infection, abscess) }\end{array}$ & $\begin{array}{l}\text { 1. fixed delay: } 30 \mathrm{~s} \text { after start } \mathrm{CM} \text { injection } \\
\text { 2. bolus tracking technique delay: } \mathrm{BT}_{100} *+15 \mathrm{~s} \\
\text { 3. test bolus technique }(0.2 \mathrm{ml} / \mathrm{kg}, \max 10 \mathrm{ml}) \text { delay: time to peak }+15 \mathrm{~s}\end{array}$ \\
\hline $\begin{array}{l}\text { Routine CT chest } \\
\text { (e.g., mass, metastases, trauma) }\end{array}$ & $\begin{array}{l}\text { 1. fixed delay: } 30-40 \mathrm{~s} \text { after start } \mathrm{CM} \text { injection } \\
\text { 2. bolus tracking technique delay: } \mathrm{BT}_{100} *+15 \mathrm{~s} \\
\text { 3. test bolus technique }(0.2 \mathrm{ml} / \mathrm{kg}, \max .10 \mathrm{ml}) \text { delay: time to peak }+15 \mathrm{~s}\end{array}$ \\
\hline $\begin{array}{l}\text { Routine CT abdomen } \\
\text { (e.g., mass, abscess, trauma) }\end{array}$ & $\begin{array}{l}\text { 1. fixed delay: } 55-60 \mathrm{~s} \text { after start } \mathrm{CM} \text { injection } \\
\text { 2. bolus tracking technique delay: } \mathrm{BT}_{100} *+35 \mathrm{~s} \\
\text { 3. test bolus technique }(0.2 \mathrm{ml} / \mathrm{kg}, \max .10 \mathrm{ml}) \text { delay: time to peak }+35 \mathrm{~s}\end{array}$ \\
\hline CTA (chest, abdomen) & $\begin{array}{l}\text { 1. bolus tracking technique delay: } \mathrm{BT}_{150} *+6 \mathrm{~s} \\
\text { 2. test bolus technique }(0.2 \mathrm{ml} / \mathrm{kg} \text {, max. } 10 \mathrm{ml}) \text { delay: time to peak }+6 \mathrm{~s} \\
\text { 3. fixed delay }<15 \mathrm{~kg}: 12-15 \mathrm{~s} \text { after start } \mathrm{CM} \text { injection**, }>15 \mathrm{~kg}: 15-20 \text { s after start } \mathrm{CM} \text { injection** }\end{array}$ \\
\hline
\end{tabular}

usually should be abandoned [53]. If further characterisation of a lesion by multiple pre- and post-CM phases is indicated, MRI is currently the preferred imaging modality of choice. Several patients will receive multiple follow-up scans [15, 54]. These scans should be kept to a minimum, and a lowdose technique often will suffice $[55,56]$. Furthermore, other imaging modalities such as US or MRI should be used if possible.

\section{Collimation}

As children are usually smaller than adults a higher spatial resolution is needed, especially along the z-axis. This can be achieved by choosing a thin collimation, thus creating an (near-) isotropic resolution of the raw dataset consisting of voxels with (nearly) equal dimensions in all directions. However, this will increase the image noise and as small children usually lack visceral fatty tissue, less noise can be tolerated than in adolescents and adults. Furthermore, in older generation scanners thin collimation negatively influences the socalled overbeaming effect resulting in an increase in radiation dose, which will be discussed later. Therefore, the choice of collimation depends on the clinical question and size of the patient and should balance the necessary z-axis resolution, gain in threedimensional (3-D) reformatting possibilities, noise level and low radiation dose level. The use of (near-) isotropic datasets is preferred for most indications, as the problem of the higher noise level usually can be solved by using the "scan thin-view thick" approach while interpreting the images (see also the "Image reconstruction" section).

\section{Pitch}

An increase in pitch can result in a shorter scan time and (in some scanner types) in a dose reduction for the patient. However, in modern MDCT scanners this may not be the best option. This is explained by the negative dose effects of the so-called overranging which will be exaggerated by increasing the pitch. Furthermore, the spatial resolution will decrease by increasing the pitch. In those scanner types in which effective mAs is used, an increase in pitch will result in an increase in the tube current. Therefore, it is usually more dose efficient to keep the pitch as low as possible $(<1)$ and if needed manually decrease the tube current, in order to achieve a similar tube current/pitch ratio (effective $\mathrm{mAs}$ ) as would be the case with a higher pitch.

\section{Scan field of view (FOV)}

The scan FOV should be tailored as much as possible to the size of the body region of interest. The major advantage of a smaller scan FOV is the higher spatial resolution, as the pixel size decreases with smaller FOV. The effect of the display FOV on resolution is often different-while some increase in resolution may result, after a certain threshold pixels are only blown up.

\section{Tube voltage $(\mathrm{kVp})$}

Due to the smaller size of children it is usually possible to lower the tube voltage with maintenance or even improvement of the diagnostic image quality and resulting in a significant dose reduction. In most children a tube voltage 
of $80-100 \mathrm{kVp}$ will suffice, especially in children with a body weight $<45 \mathrm{~kg}$. In adolescents, a tube voltage of $100 \mathrm{kVp}$ for the thorax and $120 \mathrm{kVp}$ for the abdomen is usually sufficient. However, the scanner-related parameters, such as, scanner geometry, tube filtration, detector design and efficiency, sometimes negatively influence the image quality with lower tube voltages, for instance by inducing artifacts. CT examinations with a high intrinsic contrast, such as in the chest, bones and in CTA, also justify lowering the tube voltage to $80-100 \mathrm{kVp}$. Recent studies with phantoms suggest that the optimal tube voltage in children may be even lower (approximately $60 \mathrm{kVp}$ ), at least for some indications [Kachelriess, unpublished data]. In this scope, it is appropriate to assume that slightly different tube voltages (for example $60 \mathrm{kVp}$ compared to $120 \mathrm{kVp}$ ) are related to almost similar radiobiological effects. Furthermore, the use of lower tube voltages is related to a relative reduction in the production of scattered radiation.

\section{Tube current (mA)}

By lowering the tube current a direct proportional decrease in the radiation dose is achieved with an increase in noise, a major drawback, but as long as the images are of diagnostic quality this increase in noise should and can be accepted [52]. Although several studies in phantoms have shown that the $\mathrm{mA}$ can be halved for each 3.5- to 4-cm reduction in body diameter (half value layer, HVL), in clinical practice a less stringent HVL of $4-6 \mathrm{~cm}$ is used in children. This is because small children usually lack large amounts of visceral fatty tissue and, therefore, less image noise is desirable. Based on the aforementioned, several body size or weight-based paediatric CT protocols have been suggested [33, 52, 56-59]. One vendor even has adapted the Broselow-Luten system from the emergency room into colour-coded paediatric protocols based on patient weight or length, in order to reduce errors during scanning [33, 57]. However, one has to keep in mind that the body weight alone may underestimate the dose requirements in obese children, because their body diameter may be larger than that of a taller child of identical weight.

\section{Tube rotation}

Most modern MDCT scanners apply tube rotation times of $0.3-0.5 \mathrm{~s}$ resulting in shorter examination times. This is advantageous in children as movement and respiration artifacts are reduced. Moreover, the need for sedation and anaesthesia is significantly reduced. However, one has to keep in mind that a shorter rotation time can result in a decreased number of profiles that will be used in image reconstruction, with the consequence that the image noise will increase. Therefore, in terms of image quality a rotation time of $0.5 \mathrm{~s}$ is often the best option.

\section{Radiation dose modulation techniques}

Almost all modern MDCT scanners are currently equipped with some type of automatic exposure control (AEC) or automatic tube current modulation (ATCM) technique. These techniques dynamically control the tube current during scanning based on user settings and adapted to the body geometry seen on the scanogram. In this way, image quality can be improved due to a constant noise level in all slices and radiation dose can be reduced. Modulation is possible in the axial plane (angular- or XY-modulation), along the long axis of the patient (longitudinal- or Z-modulation) or by a combination of both techniques (combined- or XYZmodulation, Fig. 2) [60].

The modulation technique and settings used differ considerably among the different vendors (Table 5) [60, 61]. Dose Right (Philips Medical Systems, Cleveland, OH, USA) asks the user to introduce reference images from prior studies into a database that will be used as reference image quality for new examinations. CARE Dose 4D (Siemens Medical Solutions, Forchheim, Germany) uses a comparable technique, with the exception that the user is asked to set a reference median effective mAs (tube current $\mathrm{x}$ rotation time/pitch) for the entire study based on a specific predefined image quality in a $20 \mathrm{~kg}$ paediatric patient $(80 \mathrm{~kg}$ for adults). The AutomA technique (GE Healthcare, Waukesha, WI, USA) uses the so-called noise index (NI), defined as the noise level in the centre of a water phantom using a reference scan method with the selected $\mathrm{kVp}, 200 \mathrm{mAs}$, selected slice thickness and a standard reconstruction kernel. Finally, Sure Exposure (Toshiba Medical Systems, Otawara-Chi, Japan) is comparable with the former system. The primary input parameter in this system is the standard deviation (SD), reflecting the noise in all positions along the $\mathrm{Z}$-axis of the patient acquired in a circular water phantom comparable to the size of the patient.

By applying ATCM techniques it is usually possible to achieve a reduction in radiation dose to the patient $[51,60,62]$. However, the amount of reduction depends largely on the user-defined settings, anatomical region scanned and, last but not least, to what extent the CT protocols already have been optimised [25, 60, 63, 64]. For instance, if ATCM is used in the chest the tube current will increase in the shoulder and liver region to maintain a constant noise level. This constant noise level 
Fig. 2 Illustration of the combined ATCM technique for CT of the abdomen. The scanogram shows the calculated variation of the mA per body part, in the frontal (green) as well as the lateral (yellow) projection (Sure Exposure 3D, Toshiba Medical Systems, Otawara, Japan)

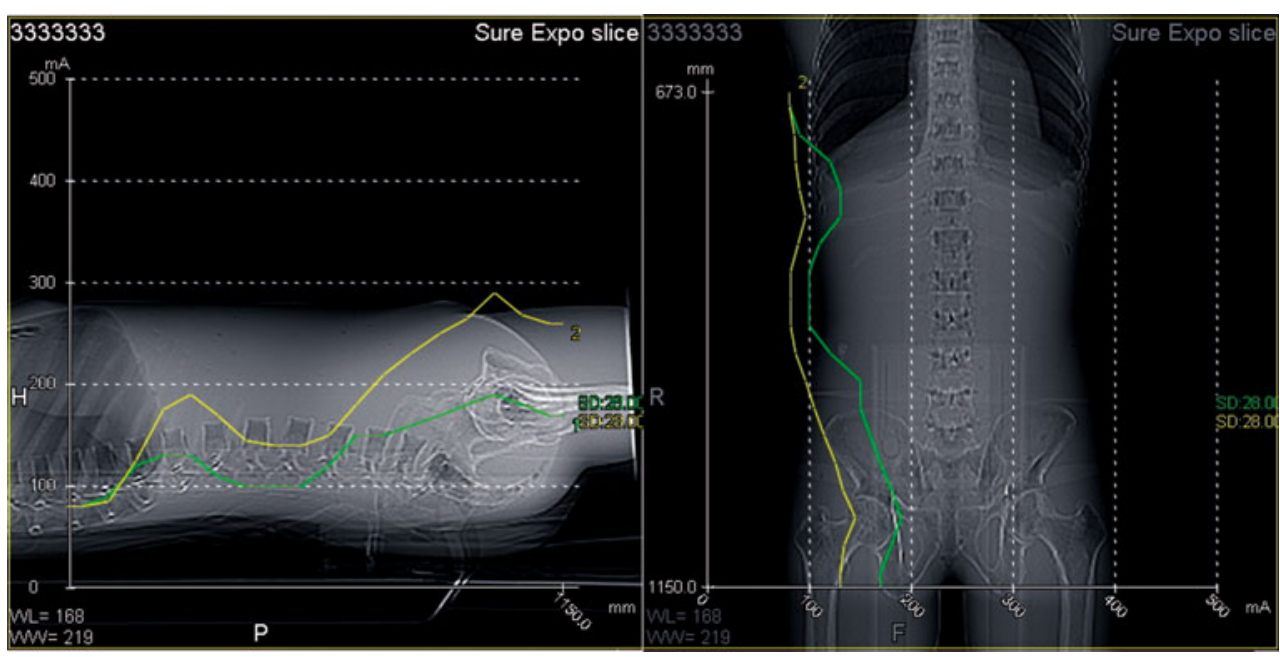

is not always necessary to answer the clinical question. The German paediatric CT survey 2005-2006 by Galanski et al. [25] showed that the ATCM techniques of GE and Toshiba correct more strictly than those of Philips and Siemens, resulting in a somewhat higher patient dose compared to manual adaptation of the CT parameters. Furthermore, specific paediatric ATCM settings are not universally available on the modern scanner systems and substantial scientific literature regarding appropriate weight-, age-, body region- and indication-based reference settings is still lacking. That is why ATCM techniques should be used with care in children.

\section{Overbeaming and overranging}

There are two dose-increasing effects that form an integral part of the image acquisition with MDCT. First, there is the overbeaming effect. In MDCT, the reconstruction algorithm requires a homogeneous illumination of all detectors. Therefore, it is necessary to widen the bundle by opening up the pre-patient collimation. This results in the formation of a penumbra outside the detector width, thereby reducing the dose efficiency (Fig. 3). The size of the penumbra depends on the focal spot size and the ratio between (a) the distance between collimator and detector, and (b) the distance between the focal spot and detector. In modern $\mathrm{CT}$ scanners the penumbra measures $1-1.5 \mathrm{~mm}$ on both sides of the collimated bundle. As the penumbra is almost constant, the dose-increasing effect of overbeaming decreases with increasing number of detectors and slice collimation width. The importance of overbeaming is minor in MDCT scanners with 32 slices and more.

The second effect is called overscanning or overranging (Fig. 4). In the helical scan mode the reconstruction algorithm requires additional raw data on both sides of the planned scan volume. These data, necessary for image reconstruction, are acquired by an additional rotation on both sides and outside the planned scan length. This will lead to radiation exposure of tissue outside the region of interest, increasing the radiation dose to the patient. The overrange length increases with increasing table movement, e.g., in case of increasing number of acquisition channels, increasing bundle collimation and/or increasing pitch. In addition, this effect is relatively more important in smaller scan lengths such as in small children. To limit the dose-increasing effect of overranging, the bundle collimation and pitch should be kept as small as possible [65].

Overbeaming and overranging always occur together but have opposite effects on the radiation exposure when changing the number of active detectors or bundle collimation. Nagel et al. [66] have calculated that for a small scan length (small children) in body CT applications, the optimal beam collimation to reduce these negative radiation dose effects will be in the order of $10-20 \mathrm{~mm}$
Table 5 Type and name of the AEC or automatic tube current modulation technique per vendor. $N / A$ not available

\begin{tabular}{llll}
\hline & Angular (XY) & Longitudinal (Z) & Combined (XYZ) \\
\hline GE & Smart Scan & Auto mA & Smart mA \\
Philips & ACS/DOM & N/A & Z-DOM \\
Siemens & Care Dose & N/A & Care Dose 4D \\
Toshiba & N/A & Sure Exposure (3D) & Sure Exposure 3D \\
\hline
\end{tabular}



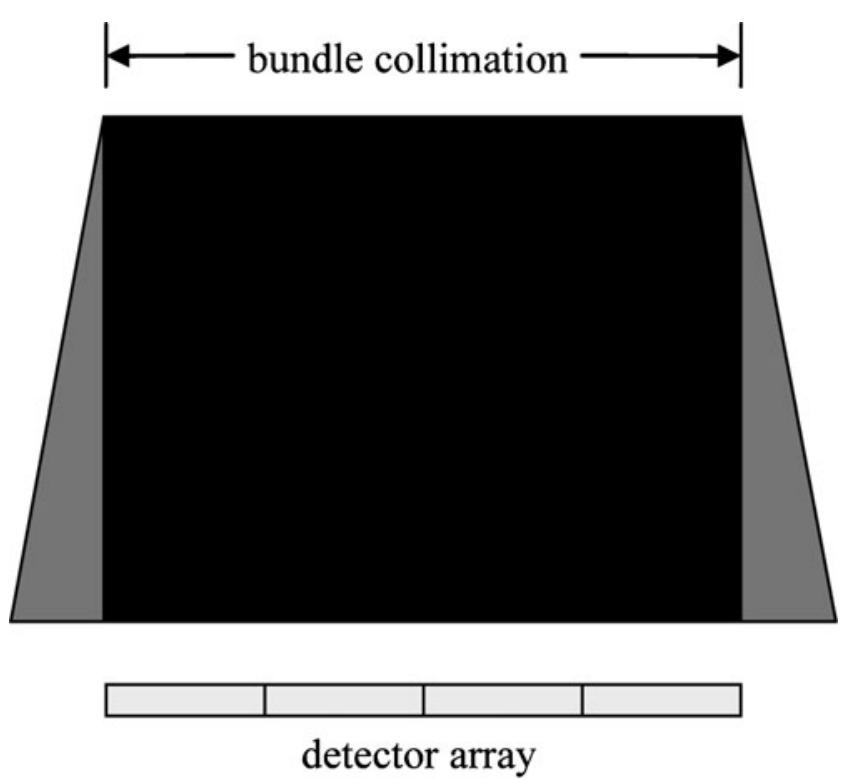

Fig. 3 Overbeaming. The X-ray bundle consists of the umbra (black) and penumbra (grey), caused by the diverging bundle. In MDCT the penumbra is excluded from detection by the detector array in order to achieve a uniform illumination of the detectors (overbeaming)

(Fig. 5). Therefore, when using a 64 slice scanner in children it will be beneficial to lower the table feed by going to a 16 -slice or 32 -slice mode, depending on the range that needs to be examined.

In modern scanners with 128 slices or more, overranging is the most important radiation dose increasing effect, limiting the use of these scanners in children. However, in the newest scanners (e.g., Philips iCT 256-slice, Toshiba Aquilion ONE 320-slice, Siemens Definition AS/AS+ 128-slice and Definition Flash dual- source 128-slice scanners) this effect has been (partly) eliminated by the introduction of so-called dynamic or adaptive collimators [67]. These collimators automatically move in and out at the beginning and end of the scan length, thereby hindering the bundle to reach the patient outside the planned scan volume. Furthermore, newer types of "step-and-shoot" scanning are also beneficial in children. In the volume scan mode the Toshiba Aquilion One 320-slice CT scanner has a scan range of $160 \mathrm{~mm}$. In neonates and infants, this scan range is sufficiently large to make a low-dose $\mathrm{CT}$ of the chest or abdomen in one rotation of $0.35-0.4 \mathrm{~s}$ without overlap or overranging. By applying two consecutive scan volumes with a small overlap it will be possible to scan relatively dose efficiently, even in older children. However, with more than three volumes, the added radiation dose from overlap becomes equivalent to the overrange effects of helical scanning.

\section{Image reconstruction}

Dose optimisation in children usually results in quite noisy $\mathrm{CT}$ datasets. When interpreting the diagnostic images, the "scan thin — view thick" principle is important. By stacking thin slices in the viewing direction, the image noise is decreased considerably whereas the resolution is maintained in all directions. However, this requires a PACS environment with adequate multi-planar reconstruction (MPR) facilities or a 3-D workstation.

When acquiring CT datasets with thin slices, it is important to realise that most image reconstruction algorithms in MDCT still have problems with the reconstruction of very thin slices. A slice thickness equal to the slice collimation is associated with an
Fig. 4 Overranging. In MDCT one section width is automatically added to the planned scan length, so image scan length is slightly longer. Furthermore, at the beginning and end of the imaged scan length an extra rotation is added, necessary for image reconstruction and resulting in a longer exposed scan length. The definition of overranging is either the difference between user planned and total exposed scan length (def 1) or the difference between total imaged and exposed scan length (def 2) (reproduced with permission from [65])

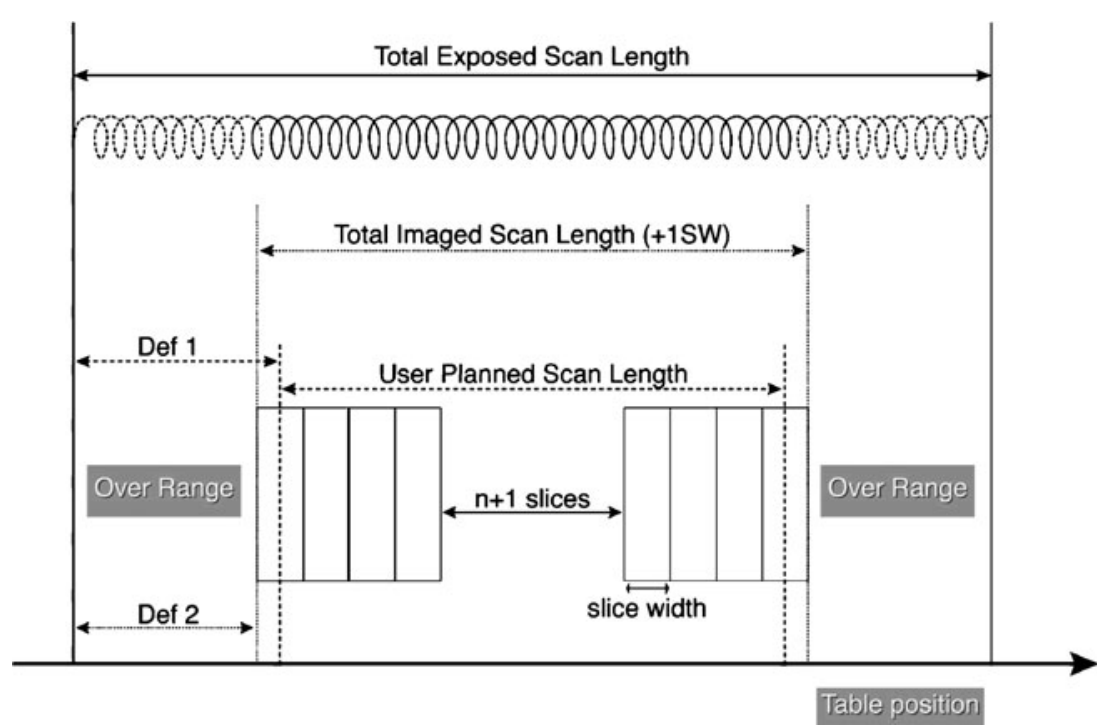



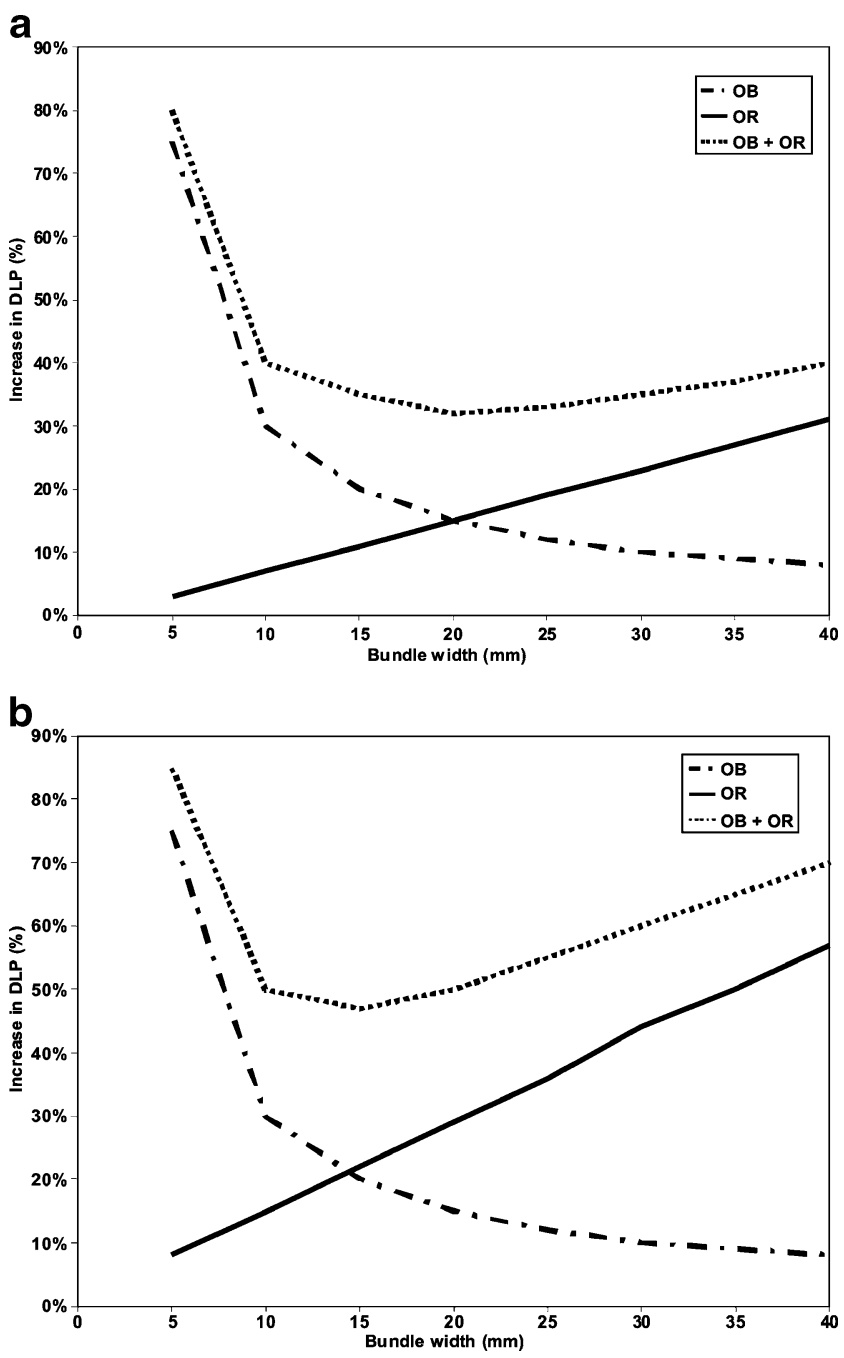

Fig. 5 Illustration of the increase in DLP (\%, vertical axis) in relation to the bundle width (mm, horizontal axis) caused by overbeaming $(\mathrm{OB})$ and overranging (OR) in MDCT. a For long scan lengths the DLP slightly changes for a bundle width $>10 \mathrm{~mm}$. b For short scan lengths (around $10 \mathrm{~cm}$, children) a bundle width of $10-20 \mathrm{~mm}$ is the most optimal in terms of radiation dose (adapted from [66], with permission)

additional amount of noise (up to $20 \%$ ), added to the expected noise of thin slices. In order to minimise this effect, it is recommended to reconstruct slightly anisotropic voxels by increasing the slice thickness by $20-40 \%$ compared to the slice collimation.

Another important aspect of image reconstruction is the relation between resolution, noise and radiation dose. The image resolution depends largely on the scan FOV, reconstruction kernel (in the scan plane) and the effective slice thickness (along the patient axis). An increase in resolution will result in an even larger increase in noise, as the noise is proportional to the fourth power of the increase in resolution. Therefore, it is important to avoid the use of overly thin slices and "hypertrophic" voxels with a smaller dimension in the
Z-axis than in the XY-plane. This can be achieved by selecting a reconstruction index that is larger than the pixel size (= FOV/matrix). With a (paediatric) FOV of $240-320 \mathrm{~mm}$ and a $512^{2}$ matrix this will be approximately $0.5-0.6 \mathrm{~mm}$.

In this scope, it is noteworthy that the image noise in reconstructed images from low-dose CT datasets can be decreased by applying a smooth reconstruction kernel. However, for the evaluation of the lung, this is usually not the optimal choice. In this case, it is better to apply a high-resolution lung or bone kernel, provided that the noise level of the dataset is not too high.

Dose calculation and optimisation

The above described optimisation of the paediatric CT protocols is mainly based on adaptation of the operatordependent scan parameters, such as $\mathrm{kVp}, \mathrm{mAs}$, collimation and pitch. However, the modern MDCT scanners made by the various manufacturers differ from one another on essential points e.g., scanner geometry, detector design and dose efficiency and collimation technique. This makes comparison among scanners difficult and exchange of protocols almost impossible.

The volume CT dose index (CTDIvol) is a commonly used dose indicator for the mean local radiation dose to the patient within a given scan volume. The CTDIvol is a function of $\mathrm{kVp}, \mathrm{mAs}$, bundle filtering, collimation and pitch. The dose length product (DLP) is an indicator of the mean effective dose to the patient of an entire CT examination. It is defined as the CTDIvol $x$ exposed scan length [68]. Both CTDIvol and DLP are better tools to optimise scanning protocols [52]. Moreover, these dose indicators allow direct comparison of the estimated radiation dose and exchange of different scanning parameter settings among scanners of different manufacturers. However, concerning the radiation dose one should realise that the CTDIvol and DLP values given on the console of most $\mathrm{CT}$ scanners nowadays are based on one or two standard (16- and 32-cm) phantoms and are usually not adjusted for patient size or weight. Therefore, these values may underestimate the actual radiation dose to the child tremendously $[69,70]$.

In case of radiation dose modulation techniques, the use of CTDIvol as an indicator of radiation dose is no longer possible, because it either corresponds to the maximum value of the modulated tube current (longitudinal modulation) or to the mean of the maximum values of the modulated tube current in AP and lateral direction (combined modulation). Only if the CTDIvol is related to the mean $\mathrm{mA}$ value (or if the mean $\mathrm{mA}$ is displayed), can it be used for comparison. 
To illustrate the aforementioned, we have included some detailed guidelines for 16-slice and 64-slice MDCT paediatric protocols (see Appendix section for Guidelines 1-3). These guidelines are based on a combination of personal experience, the state-of-the-art literature, user manuals of the different systems, supplemented by calculations using the ImPACT dose calculator (www.impactscan.org) [25, 33, 34, 50-52, 71-73]. The basis of each protocol is formed by guidelines for the CTDIvol per age or body weight category. This makes adjustment of the protocol to the restrictions in choice of parameters or in case of specific clinical questions possible.

\section{International initiatives}

It is noteworthy that several radiological and nonradiological organisations in the USA founded the "Alliance for Radiation Safety in Pediatric Imaging" in 2007. Recently, even several radiological organisations outside the USA have joined the alliance, indicating the importance of paediatric radiation safety. The website of the alliance (www.imagegently.com) provides update information about radiation-induced risks associated with diagnostic imaging and guidelines for imaging protocols for the paediatric population. A relative drawback of the website is the fact that the calculation of CT parameters is based on adult protocols with the risk of over- or under-correction when adult protocols are not optimised.

Another initiative, initially introduced by the International Commission on Radiological Protection (ICRP) in 1996 and adopted by the European Union legislation
(97/43/Euratom Directive), is the concept of developing diagnostic reference levels (DRL). DRLs are dose levels for (a selection of) typical radiological examinations for groups of standard-size patients or standard phantoms and applicable to a wide range of radiological equipment. They are usually based on (statistical) analyses of dose ranges gathered by surveys of radiological practices over a given period of time. By definition, these DRLs correspond to the 75th percentile of the observed dose distribution and they serve as dose limits that should not be exceeded under normal circumstances. Recently, several European countries have implemented this concept and DRLs are now available for a selection of representative adult and paediatric radiological examinations, including CT [25, 71-73].

\section{Conclusion}

Reducing the radiation dose and its associated risks in children should be one of the major goals of the (paediatric) radiologist, especially in MDCT. This can be achieved by (1) performing MDCT only when properly indicated (justification for scan), and (2) by adjusting the MDCT technique to the age and size of the child (optimisation). In this review, we have given an overview of the current knowledge on all aspects relevant for MDCT optimisation, in the hope that it will contribute to safer practice in children.

Open Access This article is distributed under the terms of the Creative Commons Attribution Noncommercial License which permits any noncommercial use, distribution, and reproduction in any medium, provided the original author(s) and source are credited. 


\section{Appendix}

Guideline 1 Sequential CT brain

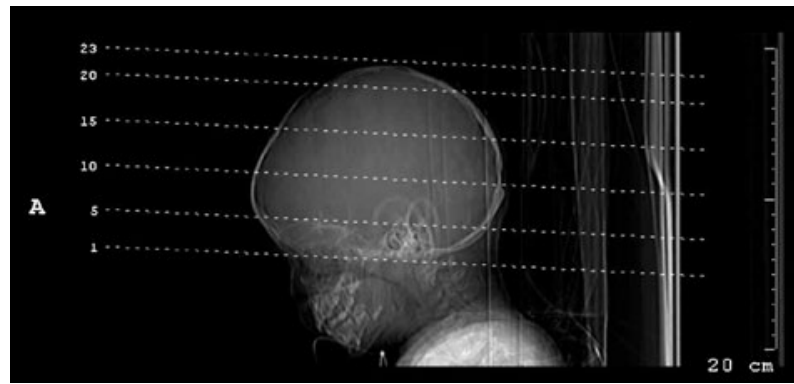

Indications:

Tumour/metastases, infection/abscess,

ischaemia/bleeding, hydrocephalus

Scan area:

Scan length:

Scan FOV:

Gantry angulations:

Method:

Rotation time:

\section{Technique}

Vertex - skull base

50-120 mm, depending on age

Head 240-250 mm

Supraorbito-meatal line (SOM)

Eye lens not in scan area!

Tube voltage $(\mathrm{kVp})$ and effective tube current $(\mathrm{mA})$ for 16 -slice CT scanners. ${ }^{*}$ Tube voltage for Philips scanners in brackets, $m$ months, $y r$ years

\begin{tabular}{|l||l|l|l|l|l|l|}
\hline Age & CTDIw & kVp $^{*}$ & GE & Philips & Siemens & Toshiba \\
\hline & & & $4 \times 1.25 \mathrm{~mm}$ & $4 \times 1.5 \mathrm{~mm}$ & $12 \times 0.75 \mathrm{~mm}$ & $4 \times 2 \mathrm{~mm}, \mathrm{M}$ \\
\hline$<6 \mathrm{~m}$ & 14.0 & $100(90)$ & 85 & 180 & 90 & 55 \\
\hline $6 \mathrm{~m}-3 \mathrm{yr}$ & 22.0 & $100(90)$ & 130 & 280 & 140 & 85 \\
\hline $3-6 \mathrm{yr}$ & 28.0 & $100(90)$ & 170 & 350 & 180 & 110 \\
\hline $6-12 \mathrm{yr}$ & 32.0 & 120 & 125 & 185 & 150 & 125 \\
\hline$>12 \mathrm{yr}$ & 50.0 & 120 & 200 & 300 & 230 & 195 \\
\hline
\end{tabular}


Tube voltage $(\mathrm{kVp})$ and effective tube current $(\mathrm{mA})$ for 64 -slice $\mathrm{CT}$ scanners. Tube voltage for Philips scanners in brackets

\begin{tabular}{|c|c|c|c|c|c|c|}
\hline Age & CTDIw & $\mathrm{kVp}^{*}$ & GE & Philips & Siemens & Toshiba \\
\hline & & & $16 \times 0.625 \mathrm{~mm}$ & $12 \times 0.625 \mathrm{~mm}$ & $10 \times 0.6 \mathrm{~mm}$ & $4 \times 2 \mathrm{~mm}, M$ \\
\hline$<6 \mathrm{~m}$ & 14.0 & $100(120)$ & 80 & 90 & 170 & 80 \\
\hline $6 \mathrm{~m}-3 \mathrm{yr}$ & 22.0 & $100(120)$ & 120 & 135 & 270 & 130 \\
\hline $3-6 \mathrm{yr}$ & 28.0 & $100(120)$ & 155 & 175 & 345 & 170 \\
\hline $6-12 \mathrm{yr}$ & 32.0 & 120 & 115 & 200 & 240 & 125 \\
\hline$>12 \mathrm{yr}$ & 50.0 & 120 & 180 & 315 & 370 & 195 \\
\hline
\end{tabular}

\section{Acquisition parameters}

Collimation:

Pitch:

Respiratory command:
See table below

Not applicable

Not applicable

\section{Reconstruction parameters}

\begin{tabular}{|l|l|l|}
\hline Reconstruction number & $\# 1$ & $\# 2$ \\
\hline Region & Infratentorial & Supratentorial \\
\hline Slice thickness (mm) & $2.5-4$ & $5-8$ \\
\hline Reconstruction index & $2.5-4$ & $5-8$ \\
\hline Reconstruction kernel & Brain & Brain \\
\hline Window width/level & $150 / 40$ & $80 / 40$ \\
\hline
\end{tabular}




\section{Contrast injection}

Injection type:

Manual or injector; maximum 150 psi

Contrast type:

Non-ionic CM 300 mg I/ml

Contrast dose:

$1.5 \mathrm{ml} / \mathrm{kg}$ with a maximum of $100 \mathrm{ml}$ (dose $450 \mathrm{mg} \mathrm{I} / \mathrm{kg}$ )

Injection Duration:

$30 \mathrm{~s}$

Flow rate:

0.05-0.07 ml/kg/s (flux 15-20 mg I/kg/s)

Flush: Yes, $0.9 \%$ sodium chloride flush over 3-4 s with identical

flow rate

Scan delay:

Fixed, $60 \mathrm{~s}$ after beginning of the CM injection

\section{Remarks}

For follow-up of hydrocephalus the radiation dose can be lowered by approximately $30 \%$. 
Guideline 2 CT chest-mass

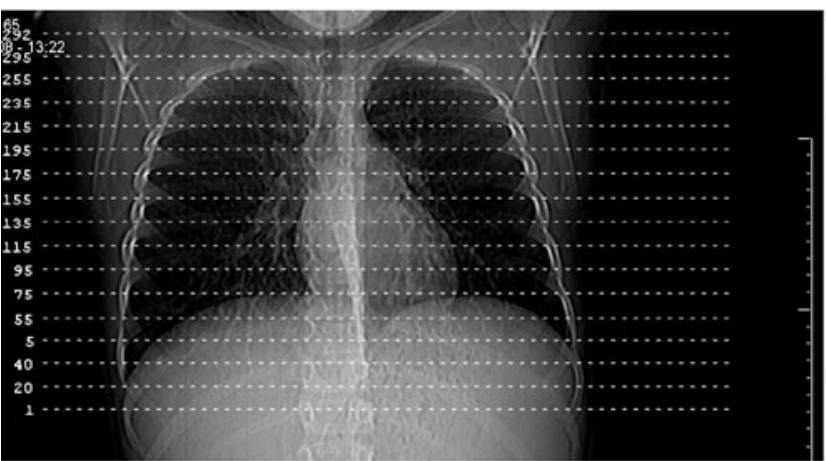

Indications:

Masses, lymphoma, metastases, trauma,

infection/abscess

Scan area:

Scan length:

Scan FOV:

Position:

Gantry angulations:
Thorax inlet - costophrenic angle

120-200 mm, depending on age

Body $500 \mathrm{~mm}$ (320 mm M-field on Toshiba possible)

Supine, arms up

None

\section{Technique}

Method:

Helical

Rotation time:

$0.5 \mathrm{~s}$ (if necessary $0.3-0.4 \mathrm{~s}$; adjust $\mathrm{mA}$ )

Tube voltage $(\mathrm{kV})$ and effective tube current $(\mathrm{mA})$ for 16-slice CT scanners. * Tube voltage for Philips scanners in brackets

\begin{tabular}{|l||c||c||c|c|c|c|}
\hline Weight & CTDIvol & kV $^{*}$ & GE & Philips & Siemens & Toshiba \\
\hline & & & $16 \times 1.25 \mathrm{~mm}$ & $16 \times 0.75 \mathrm{~mm}$ & $16 \times 0.75 \mathrm{~mm}$ & $16 \times 1 \mathrm{~mm}, \mathrm{M}$ \\
\hline $4-9 \mathrm{~kg}$ & 1.6 & $80(90)$ & 120 & 90 & 125 & 90 \\
\hline $10-19 \mathrm{~kg}$ & 2.0 & $80(90)$ & 150 & 115 & 160 & 110 \\
\hline $20-29 \mathrm{~kg}$ & 2.4 & $100(90)$ & 80 & 135 & 90 & 70 \\
\hline $30-39 \mathrm{~kg}$ & 2.8 & $100(90)$ & 95 & 160 & 105 & 85 \\
\hline $40-49 \mathrm{~kg}$ & 3.5 & $100(90)$ & 120 & 200 & 135 & 105 \\
\hline $50-64 \mathrm{~kg}$ & 4.3 & $100(90)$ & 150 & 245 & 165 & 130 \\
\hline
\end{tabular}


Tube voltage $(\mathrm{kV})$ and effective tube current $(\mathrm{mA})$ for 64-slice CT scanners. * Tube voltage for Philips scanners in brackets

\begin{tabular}{|c||c|c||c|c|c|c|}
\hline Weight & CTDIvol & $\mathbf{k V}^{*}$ & GE & Philips & Siemens & Toshiba \\
\hline & & & $32 \times 0.625 \mathrm{~mm}$ & $16 \times 0.625 \mathrm{~mm}$ & $32 \times 0.6 \mathrm{~mm}$ & $32 \times 0.5 \mathrm{~mm}, M$ \\
\hline $4-9 \mathrm{~kg}$ & 1.6 & 80 & 90 & 95 & 175 & 90 \\
\hline $10-19 \mathrm{~kg}$ & 2.0 & 80 & 110 & 120 & 220 & 110 \\
\hline $20-29 \mathrm{~kg}$ & 2.4 & $100(120)$ & 75 & 140 & 120 & 70 \\
\hline $30-39 \mathrm{~kg}$ & 2.8 & $100(120)$ & 85 & 70 & 135 & 85 \\
\hline $40-49 \mathrm{~kg}$ & 3.5 & $100(120)$ & 105 & 90 & 170 & 105 \\
\hline $50-64 \mathrm{~kg}$ & 4.3 & $100(120)$ & 130 & 110 & 210 & 130 \\
\hline
\end{tabular}

\section{Acquisition parameters}

Collimation:

Pitch

Respiratory command:

\section{See table below}

16-slice $0.56-0.95$

64-slice $0.52-0.95$

If possible scan during inspiration (child $>5$ years)

\section{Reconstruction parameters}

\begin{tabular}{|l|l|l|l|l|}
\hline Reconstruction number & $\# 1$ & $\# 2$ & $\# 3$ & $\# 4$ \\
\hline Slice thickness (mm) & $0.75-1.0$ & $0.75-1.0$ & $3-5$ & $3-5$ \\
\hline Reconstruction index & $0.6-0.8$ & $0.6-0.8$ & $2-4$ & $2-4$ \\
\hline Reconstruction kernel & Soft tissue & Lung & Soft tissue & Lung \\
\hline Window width/level & $450 / 60$ & $1,500 /-500$ & $450 / 60$ & $1,500 /-500$ \\
\hline
\end{tabular}




\section{Contrast injection}

Injection type:

Contrast type:

Contrast dose:

Injection time:

Flow rate:

Flush:

Bolus tracking:

Bolus tracking ROI:

Bolus tracking threshold:

Scan delay:

Alternatives:
Power injector; maximum 150 psi

Non-ionic CM 300 mg I/ml

$1.5 \mathrm{ml} / \mathrm{kg}$ with a maximum of $100 \mathrm{ml}$ (dose $450 \mathrm{mg} \mathrm{I} / \mathrm{kg}$ )

$30 \mathrm{~s}$

$0.05 \mathrm{ml} / \mathrm{kg} / \mathrm{s}$ (iodine flux $15 \mathrm{mg} \mathrm{I} / \mathrm{kg} / \mathrm{s}$ )

Yes, $0.9 \%$ sodium chloride flush during 3-4 s with identical

flow rate

Yes

Descending thoracic aorta, proximal

$+100 \mathrm{HU}$ (above baseline HU)

$\mathrm{BT} 100 *+15 \mathrm{~s}$

Peak test bolus injection $(0.2 \mathrm{ml} / \mathrm{kg} @ 0.05 \mathrm{ml} / \mathrm{kg} / \mathrm{s})+15 \mathrm{~s}$

Fixed, $30 \mathrm{~s}$ after start injection when $<20 \mathrm{~kg}$

Fixed, $40 \mathrm{~s}$ after start injection when $>20 \mathrm{~kg}$

\section{Remarks}

*BT100 is the time required to reach a threshold of $+100 \mathrm{HU}$ with bolus tracking (BT). BT systems have built in delays of which the exact duration is often not clear. This delay may increase when table movement is necessary before starting the scan. Examples of bolus tracking systems are: Smart Prep (GE), Bolus Pro Ultra (Philips), CARE Bolus (Siemens), and Sure Start (Toshiba) 
Guideline 3 CT abdomen-mass

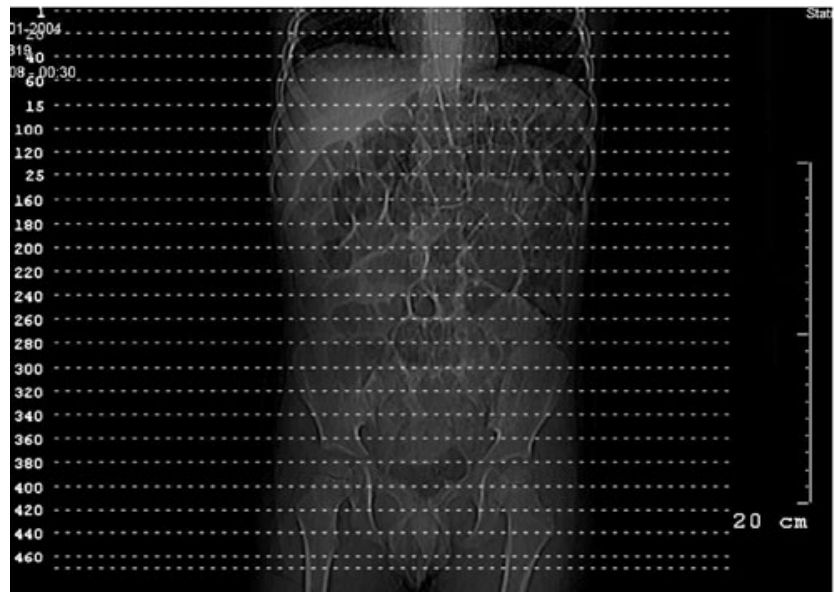

Indications:

Abdominal mass, lymphoma, appendicitis, trauma,

abscess

Scan area: $\quad$ Diaphragm - pubic symphysis

Scan length:

220-400 mm, depending on age

Scan FOV:

Body 500 mm (320 mm M-field on Toshiba possible)

Position:

Supine, arms up

Gantry angulations:

None

\section{Technique}

Method:

Helical

Rotation time:

$0.5 \mathrm{~s}$

Tube voltage $(\mathrm{kVp})$ and effective tube current $(\mathrm{mA})$ for 16-slice $\mathrm{CT}$ scanners. ${ }^{*}$ Tube voltage for Philips scanners in brackets

\begin{tabular}{|l|l|l|l|l|l|l|}
\hline Weight & CTDIvol & kV** & GE & Philips & Siemens & Toshiba \\
\hline & & & $16 \times 1.25 \mathrm{~mm}$ & $16 \times 0.75 \mathrm{~mm}$ & $16 \times 0.75 \mathrm{~mm}$ & $16 \times 1 \mathrm{~mm}, M$ \\
\hline $4-9 \mathrm{~kg}$ & 2.1 & $100(90)$ & 80 & 120 & 80 & 50 \\
\hline $10-19 \mathrm{~kg}$ & 3.0 & $100(90)$ & 110 & 170 & 115 & 70 \\
\hline $20-29 \mathrm{~kg}$ & 3.8 & $100(90)$ & 140 & 215 & 145 & 90 \\
\hline $30-39 \mathrm{~kg}$ & 4.1 & $100(90)$ & 150 & 235 & 155 & 95 \\
\hline $40-49 \mathrm{~kg}$ & 4.9 & 120 & 100 & 125 & 120 & 95 \\
\hline $50-64 \mathrm{~kg}$ & 5.9 & 120 & 120 & 150 & 140 & 115 \\
\hline
\end{tabular}


Tube voltage $(\mathrm{kV})$ and effective tube current $(\mathrm{mA})$ for 64-slice CT scanners. * Tube voltage for Philips scanners in brackets

\begin{tabular}{|l||l|l||l|l|l|l|}
\hline Weight & CTDIvol & kV** & GE & Philips & Siemens & Toshiba \\
\hline & & & $32 \times 0.625 \mathrm{~mm}$ & $16 \times 0.625 \mathrm{~mm}$ & $32 \times 0.6 \mathrm{~mm}$ & $32 \times 0.5 \mathrm{~mm}, \mathrm{M}$ \\
\hline $4-9 \mathrm{~kg}$ & 2.1 & $100(80)$ & 60 & 130 & 105 & 50 \\
\hline $10-19 \mathrm{~kg}$ & 3.0 & $100(80)$ & 90 & 180 & 145 & 70 \\
\hline $20-29 \mathrm{~kg}$ & 3.8 & $100(120)$ & 115 & 90 & 185 & 90 \\
\hline $30-39 \mathrm{~kg}$ & 4.1 & $100(120)$ & 125 & 105 & 200 & 95 \\
\hline $40-49 \mathrm{~kg}$ & 4.9 & 120 & 100 & 125 & 140 & 95 \\
\hline $50-64 \mathrm{~kg}$ & 5.9 & 120 & 120 & 150 & 170 & 115 \\
\hline
\end{tabular}

\section{Acquisition parameters}

Collimation:

Pitch:

Respiratory command:
See table below

16-slice $0.56-0.95$

64-slice $0.52-0.95$

If possible scan during inspiration (child older than 5 years)

\section{Reconstruction parameters}

\begin{tabular}{|l|l|l|}
\hline Reconstruction number & $\# 1$ & $\# 2$ \\
\hline Slice thickness (mm) & $0.75-1.0$ & $3-5$ \\
\hline Reconstruction index & $0.6-0.8$ & $2-4$ \\
\hline Reconstruction kernel & Soft tissue & Soft tissue \\
\hline Window width/level & $450 / 60$ & $450 / 60$ \\
\hline
\end{tabular}




\section{CMt injection}

$\begin{array}{ll}\text { Injection type: } & \text { Power injector; maximum } 150 \mathrm{psi} \\ \text { CM type: } & \text { Non-ionic CM } 300 \mathrm{mg} \mathrm{I} / \mathrm{ml} \\ \text { CM dose: } & 2.0 \mathrm{ml} / \mathrm{kg} \text { with maximum of } 100 \mathrm{ml} \text { (dose } 600 \mathrm{mg} \mathrm{I} / \mathrm{kg}) \\ \text { Injection time: } & 30 \mathrm{~s} \\ \text { Flow rate: } & 0.07 \mathrm{ml} / \mathrm{kg} / \mathrm{s} \text { (iodine flux } 20 \mathrm{mg} \mathrm{I} / \mathrm{kg} / \mathrm{s}) \\ \text { Flush: } & \text { Yes, } 0.9 \% \text { sodium chloride flush over } 3-4 \mathrm{~s} \text { with identical } \\ & \text { flow rate } \\ \text { Bolus tracking: } & \text { Yes } \\ \text { Bolus tracking ROI: } & \text { Abdominal aorta, proximal } \\ \text { Bolus tracking threshold: } & +100 \mathrm{HU} \text { (above baseline HU) } \\ \text { Scan delay: } & \text { BT100 }+35 \mathrm{~s} \\ \text { Alternatives: } & \text { Peak test bolus injection }(0.2 \mathrm{ml} / \mathrm{kg} @ 0.7 \mathrm{ml} / \mathrm{kg} / \mathrm{s})+35 \mathrm{~s}\end{array}$

Fixed, $55 \mathrm{~s}$ after start injection when $<20 \mathrm{~kg}$

Fixed, $60 \mathrm{~s}$ after start injection when $>20 \mathrm{~kg}$

\section{References}

1. Slovis TL (2002) The ALARA (as low as reasonably achievable) concept in pediatric CT intelligent dose reduction. ALARA conference proceedings. Pediatr Radiol 32:217-218

2. Brenner DJ, Hall EJ (2007) Computed tomography-An increasing source of radiation exposure. N Engl J Med 357:2277-2284

3. Hall EJ, Brenner DJ (2008) Cancer risks from diagnostic radiology. BJR 81:362-378

4. Smith-Bindman R, Lipson J, Marcus R et al (2009) Radiation dose associated with common computed tomography examinations and the associated lifetime attributable risk of cancer. Arch Intern Med 169:2078-2086

5. Berrington de González A, Mahesh M, Kim KP et al (2009) Projected cancer risks from computed tomography scans performed in the United States in 2007. Arch Intern Med 169:20712077

6. ICRP-103 (2007) The 2007 Recommendations of the International Commission on Radiological Protection. ICRP publication 103. Ann ICRP 37:1-332

7. Semelka RC, Armao DM, Elias J et al (2007) Imaging strategies to reduce the risk of radiation in CT studies, including selective substitution with MRI. J Magn Reson Imaging 25:900-909

8. Mezrich R (2008) Are CT scans carcinogenic? J Am Coll Radiol 5:691-693

9. Frush DP (2009) Radiation, CT, and Children: the simple answer is... It's complicated. Radiology $252: 4-6$
10. Little MP, Wakeford R, Tawn EJ et al (2009) Risks associated with low doses and low dose rates of ionizing radiation: why linearity may be (almost) the best we can do. Radiology 251:6-12

11. Tubiana M, Feinendegen LE, Yang $C$ et al (2009) The linear nothreshold relationship is inconsistent with radiation biologic and experimental data. Radiology 251:13-22

12. Arch ME, Frush DP (2008) Pediatric body MDCT: a 5-year follow-up survey of scanning parameters used by pediatric radiologists. AJR 191:611-617

13. Brody AS, Frush DP, Huda W et al (2007) Radiation risk to children from computed tomography. Pediatrics 120:677-682

14. Hillman BJ (2008) Radiation exposure and imaging utilization. J Am Coll Radiol 5:689-690

15. Robbins E (2008) Radiation risks from imaging studies in children with cancer. Pediatr Blood Cancer 51:453-457

16. Cohen MD (2009) Pediatric CT radiation dose: how low can we go? AJR 192:1292-1303

17. Redberg RF (2009) Cancer risks and radiation exposure from computed tomograpic scans: how can we be sure that the benefit outweighs the risks? Arch Intern Med 169:2049-2050

18. Boland GW (2008) The CT dose and utilization controversy: the radiologist's response. J Am Coll Radiol 5:696-698

19. Fenton SJ, Hansen KW, Meyers RL et al (2004) CT scan and the pediatric trauma patient: are we overdoing it? J Pediatr Surg 39:1877-1881

20. Donnelly LF (2005) Reducing radiation dose associated with pediatric CT by decreasing unnecessary examinations. AJR 184:655-657 
21. Oikarinen H, Meriläinen S, Pääkkö E et al (2009) Unjustified CT examinations in young patients. Eur Radiol 19:1161-1165

22. Shiralkar S, RennieA SM et al (2003) Doctor's knowledge of radiation exposure: questionnaire study. BMJ 327:371-372

23. Lee CI, Haims AH, Monico EP et al (2004) Diagnostic CT scans: assessment of patient, physician, and radiologist awareness of radiation dose and possible risks. Radiology 231:393-398

24. Thomas KE, Parnell-Parmley JE, Haidar S et al (2006) Assessment of radiation dose awareness among pediatricians. Pediatr Radiol 36:823-832

25. Galanski M, Nagel HD, Stamm G (2006) Pediatric CT exposure practice in the Federal Republic of Germany. Results of a nationwide survey in 2005/06. Medizinische Hochschule Hannover. http://www.drg-apt.de/

26. Riccabona M (2003) Thoracic sonography in infancy and childhood. Radiologe 43:1075-1089

27. Riccabona M (2008) Ultrasound of the chest in children (mediastinum excluded). Eur Radiol 18:390-399

28. Darge K, Jaramillo D, Siegel MJ (2008) Whole-body MRI in children, Current status and future applications. Eur J Radiol 68:289-298

29. American College of Radiology ACR (2008) ACR appropriateness criteria, October 2008 version. http://www.acr.org/default. aspx

30. The Royal College of Radiologists (2009) Making the best use of clinical radiology services, Referral guidelines. 6th edn (MBUR6) http://www.rcr.ac.uk

31. Taghon TA, Bryan YF, Kurth CD (2006) Pediatric radiology sedation and anesthesia. Int Anesthesiol Clin 44:64-79

32. Shankar VR (2008) Sedating children for radiological procedures: an intensivist's perspective. Pediatr Radiol 38:S213-S217

33. Frush DP (2008) MDCT in children: scan techniques and contrast issues. In: Kalra MK, Sanjay S, Rubin GD (eds) Multidetector CT: from protocols to practice, 1st edn. Springer Verlag, Heidelberg, pp 331-351

34. Siegel MJ (2008) Practical CT techniques. In: Siegel MJ (ed) Pediatric body CT, 2nd edn. Lippincott Williams \& Wilkins, Philadelphia, pp 1-32

35. Hebert JJ, Taylor AJ, Winter TC et al (2006) Low-attenuation oral GI contrast agents in abdominal-pelvic computed tomography. Abdom Imaging 31:48-53

36. Koo CW, Shah-Patel LR, Baer JW et al (2008) Cost-effectiveness and patient tolerance of low-attenuation oral contrast material: milk versus VoLumen. AJR 190:1307-1313

37. Schwab SA, Uder M, Anders K et al (2009) Peripheral intravenous power injection of iodinated contrast media through $22 \mathrm{G}$ and 20G cannulas: can high flow rates be achieved safely? A clinical feasibility study. RoFo 181:355-361

38. Herts BR, O'Malley CM, Wirth SL et al (2001) Power injection of contrast media using central venous catheters: feasibility, safety, and efficacy. AJR 176:447-453

39. Gebauer B, Teichgräber UK, Hothan T et al (2005) Contrast media pressure injection using a portal catheter system - results of an in vitro study. Rofo 177:1417-1423

40. Rigsby CK, Gasber E, Seshadri R et al (2007) Safety and efficacy of pressure-limited power injection of iodinated contrast medium through central lines in children. AJR 188:726-732

41. Zamos DT, Todd TM, Patton HA et al (2007) Injection rate threshold for triple-lumen central venous catheter. An in vitro study. Acad Radiol 14:574-578

42. Fleishmann D, Kamaya A (2009) Optimal vascular and parenchymal contrast enhancement: the current state of the art. Radiol Clin North Am 47:13-26

43. Bae KT, Heiken JP (2005) Scan and contrast administration principles of MDCT. Eur Radiol 15:E46-59
44. Bae KT, Shah AJ, Shang SS et al (2008) Aortic and hepatic contrast enhancement with abdominal 64-MDCT in pediatric patients: effect of body weight and iodine dose. AJR 191:15891594

45. Fricke BL, Donnelly LF, Frush DP et al (2003) In-plane bismuth breast shields for pediatric CT: effects on radiation dose and image quality using experimental and clinical data. AJR 180:407411

46. Coursey C, Frush DP, Yoshizumi T et al (2008) Pediatric chest MDCT using tube current modulation: effect on radiation dose with breast shielding. AJR 190:W54-W61

47. Vollmar SV, Kalender WA (2008) Reduction of dose to the female breast in thoracic CT: a comparison of standard-protocol, bismuthshielded, partial and tube-current-modulated CT examinations. Eur Radiol 18:1674-1682

48. Geleijns J, Salvadó Artells M, Veldkamp WJH et al (2006) Quantitative assessment of selective in-plane shielding of tissues in computed tomography through evaluation of absorbed dose and image quality. Eur Radiol 16:2334-2340

49. Leswick DA, Hunt MM, Webster ST et al (2008) Thyroid shields versus $\mathrm{Z}$-axis automatic tube current modulation for dose reduction at neck CT. Radiology 249:572-580

50. Vock P, Wolf R (2007) Dose optimization and reduction in CT of children (chapter 15). In: Tack D, Gevenois PA (eds) Radiation dose from adult and pediatric multidetector computed tomography. Springer, Berlin, pp 223-236

51. Singh S, Kalra MK, Moore MA et al (2009) Dose reduction and compliance with pediatric CT protocols adapted to patient size, clinical indication, and number of prior studies. Radiology 252:200-208

52. Verdun FR, Gutierrez D, Schnyder PF et al (2007) CT dose optimization when changing to CT multi-detector row technology. Curr Probl Diagn Radiol 36:176-184

53. Da Costa e Silva EJ, Da Silva GA (2007) Eliminating unenhanced CT when evaluating abdominal neoplasms in children. AJR 189:1211-1214

54. Sodickson A, Baeyens PF, Andriole KP et al (2009) Recurrent CT, cumulative radiation exposure, and associated radiation-induced cancer risks from CT of adults. Radiology 251:175-184

55. Udayansankar UK, Braithwaite K, Arvaniti M et al (2008) Lowdose nonenhanced head CT protocol for follow-up evaluation of children with ventriculoperitoneal shunt: reduction of radiation and effect on image quality. AJNR 29:802-806

56. Shah R, Gupta AK, Rehani MN et al (2005) Effect of reduction of tube current on reader confidence in paediatric computed tomography. Clin Radiol 60:224-231

57. Frush DP, Soden B, Frush KS et al (2002) Improved pediatric multidetector body CT using a size-based color-coded format. AJR 178:721-726

58. Kotre CJ, Willis SP (2003) A method for the systematic selection of technique factors in paediatric CT. BJR 76:51-56

59. Paterson A, Frush DP (2007) Dose reduction in paediatric MDCT: general principles. Clin Radiol 62:507-517

60. Lee CH, Goo JM, Lee HJ et al (2008) Radiation dose modulation techniques in the multidetector $\mathrm{CT}$ era: From basics to practice. Radiographics 28:1451-1459

61. McCollough CH, Primak AN, Braun N et al (2009) Strategies for reducing radiation dose in CT. Radiol Clin North Am 47:27-40

62. Smith AB, Dillon WP, Lau BC et al (2008) Radiation dose reduction strategy for $\mathrm{CT}$ protocols: successful implementation in neuroradiology section. Radiology 247:499-506

63. Kalra MK, Maher MM, Toth TL et al (2004) Techniques and applications of automatic tube current modulation for CT. Radiology 233:649-657

64. Kalender WA, Buchenau S, Deak P et al (2008) Technical approaches to the optimisation of CT. Phys Med 24:71-79 
65. Van der Molen AJ, Geleijns J (2007) Overranging in multisection CT: quantification and relative contribution to dose-comparison of four 16-section CT-scanners. Radiology 242:208-216

66. Nagel HD (2007) CT parameters that influence the radiation dose. In: Tack D, Gevenois PA (eds) Radiation dose from adult and pediatric multidetector computed tomography. Springer, Berlin, pp 51-79

67. Deak PD, Lagner O, Lell M et al (2009) Effects of adaptive section collimation on patient radiation dose in multisection spiral CT. Radiology 252:140-147

68. Thomas KE, Wang B (2008) Age-specific effective doses for pediatric MSCT examinations at a large children's hospital using DLP conversion coefficients: a simple estimation method. Pediatr Radiol 38:645-656
69. Fujii K, Aoyama T, Koyama S et al (2007) Comparative evaluation of organ and effective doses of paediatric patients with those for adults in chest and abdominal CT examinations. BJR 80:657-667

70. Huda W, Vance A (2007) Patient radiation doses from adult and pediatric CT. AJR 188:540-546

71. Shrimpton PC, Hillier MC, Lewis MA et al (2006) National survey of doses from CT in the UK: 2003. Br J Radiol 79:968 980

72. Verdun FR, Gutierrez D, Vader JP et al (2008) CT radiation dose in children: a survey to establish age-based diagnostic reference levels in Switzerland. Eur Radiol 18:1980-1986

73. Brisse HJ, Aubert B (2009) CT exposure from pediatric MDCT: results from the 2007-2008 SFIPP/ISRN survey. J Radiol 90:207-215 